\title{
The Unseen Water: Experimentation with Scientific Photomicrography and Creative Coding
}

\author{
Anastasia Tyurina \\ Griffith University \\ Unit 1b, 351 Troughton Rd, Coopers Plains, QLD, 4108, Australia \\ anastasia.tyurina@grifithuni.edu.au
}

\section{INTRODUCTION}

This research involves aesthetic approaches to scientific photomicrography. Specifically, this project investigates the reinterpretation of photomicrographic images of micro-scale drops of water made by a Scanning Electron Microscope (SEM), a tool that has expanded the boundaries of observation and representation of the micro world since it was introduced to scientific research in the mid-1960s. I was not aiming to produce scientific records through my use of the SEM; instead, like several artists before me, I used scientific photography methods to create aesthetic images. By exploring the interplay between the indexical and iconic modalities in the process of creating photomicrographs, I seek to imbue them with new meanings and re-appropriate scientific photography as a creative practice and a source of science communication to the general public. Building on the fact that scientific and digital tools have brought new ways of seeing the world, my artistic application of them seeks to extend our perception. This paper provides an explanation of the production of interactive artworks for my project. In these works, viewers are encouraged to engage with photomicrographs of water through touch and movement, which resembles human interaction with water.

\section{THE RIPPLE EFFECT}

The primary purpose of my doctoral visual art project is to depict the inherent features of water that are invisible to the eye through using the SEM. To do so, I used the process of evaporation as an alternative and unusual artistic method of visually presenting the composition of water. My approach is unique in the specific way in which I use water to create images using the SEM. During experiments for my project, it became evident that the structure of water impurities is visually transformed after evaporation and reveals a unique connection between evaporation and solidification. This process of revealing the nature of water (water chemistry) allowed me to play with the process like an artist.

In a sense, my artworks employ two kinds of medium, comprising two different applications of SEM photomicrography: still photomicrographs and interactive digital installations. They can be perceived differently in terms of the aesthetic response they generate in the viewer, but both draw attention to the qualities of water through enhanced visual details that aid in the interpretation of water samples. I use static SEM-generated photomicrographs of water, then apply a digital code which allows the image to be altered by the audience's interaction with its touch-sensitive interface. Thus, anyone who touches the screen can create, display and experience a ripple effect, which is very similar to the effect we can see and observe when we interact with water surface by touching or disturbing it. Interacting with the scientific photomicrographs in this way offers a layered meaning and can enhance the audience's perception of scientific data, scientific photography, and water.

\section{THE NEW WAY OF SEEING WATER}

The composition of water, even that which is entirely free from mineral and organic impurities, is complex and diverse because water is constantly in contact with all sorts of substances. During experiments for my project, the structure of the water impurities visually transforms and leads to a unique connection between evaporation and solidification (Yakhno et al. 2005). After the evaporation, water is no longer a liquid; dry solids or other substances become watermarks, which 
represent what is water composition. This natural process of drying reveals the unique, informative capacity of droplets as well as the shapes, patterns, details, and characteristics of water (Kokornaczyk et al. 2011). Desiccated drops of water that were attacked by secondary electrons look different from one another in the same environmental conditions. In other words, the structure of water visually represented by the SEM can be seen as an alternative and unusual method of visually presenting the composition of water.

\section{PHOTOMICROGRAPHS MADE BY THE SEM}

Images made by the SEM are beyond light because the process of producing a picture is camera-less; captured by a focused beam of electrons, they are not photographs. However, electron detector named Everhart-Thornley, used in scanning electron microscopy typically utilises a scintillator, a material which produces light when an electron collides with it. So, the SEM does use photons. But these photons are converted back into electrons which are accelerated onto the electrodes of the photomultiplier, producing an increasing electrons stream until the final collector is reached.

Thus, this process is different from the work of light involved in creating a photograph. Controlled by sophisticated computer software the SEM apparatus generate the images on a screen where each pixel represents some information encoded into a visual analogue (Burgess et al. 1990, Breger 1995). The apparatus tries to recreate a reality that is not a visual phenomenon, which scientists then try to analyse through its visual representation: the photomicrograph. Interestingly, pixels constructed by a device are already interpreted as a picture even though the phenomenon they register may not be visible and hence require further interpretation by scientists.

The interpretation of the imagery produced by the SEM is confusing because the microscopic sample seems as if it is illuminated by the detector and observed in the eye aperture. Even though light seems to come from a particular illuminant, the contrast depends on atomic weight, chemical surface properties, crystallographic properties, the microtopography of the sample and the tilt of the plate, with a sample positioned to the electron beam that hits it.

\section{SCIENTIFIC IMAGES AND NEW MEDIA}

Exploring the idea of 'interactivity' for my project, I looked for a method that allows viewers to interact with photographs by altering the work's visual content. Utilising the programming language Processing, I developed an algorithm which allows viewers to physically interact with my photomicrographs so that they become direct objects of manipulation. Using the random human touch of some areas of the developed algorithm alters the static image, which in some senses visually represents non-visual elements: scientific data.

Through my research, I have explored different digital tools and realised that creative coding suits my goals because this type of computer programming is designed to create something expressive instead of something functional. Using creative coding tool such as Processing, it is possible to create art installations, projections, sound art installations, and much more within the context of the visual arts.

The interplay between virtual ripple effects and the resemblance of physical interaction with water can be understood as embodying the "artist-displayuser" paradigm seen in regards to computer art (Juliff \& Cox 2015). In their article "The PostDisplay Condition of Contemporary Computer Art", Toby Juliff and Travis Cox attempt to reconceptualise the relationship between artistic intentionality, coding, interface, and user input. They suggest that the relationship between the artist and computer code should be reconsidered so that the paradigm becomes "artist-codedisplay-user." They state that "the code takes input from the user and subjects it to internal semiosis between distinct elements of the code, before being output to the display.

"This code, having been written by the artist, or an agent of the artist, contains within its structure an inbuilt intentionality, a way of approaching input that is integral to conveying the intended meaning." (Juliff \& Cox 2015, p. 10).

In line with artists using code to activate new experiences and with Juliff and Cox, who argue that the code is not only a product of intention and meaning but also a producer of them, I seek in my practice to explore the role of code in the production of meaning, in particular for the scientific photomicrograph of natural phenomena.

In the series of live images for my project, the photomicrographs displayed on the screen seem to be still when viewed from a distance; yet, as the audience comes closer and start touching the screen, the ripples appear.

The photomicrograph transforms into a live picture, producing varying forms of ripple that seem both ordered and random at the same time. Such transformations occur continuously until the userviewer stops touching the screen (Figures 1 and 2). 


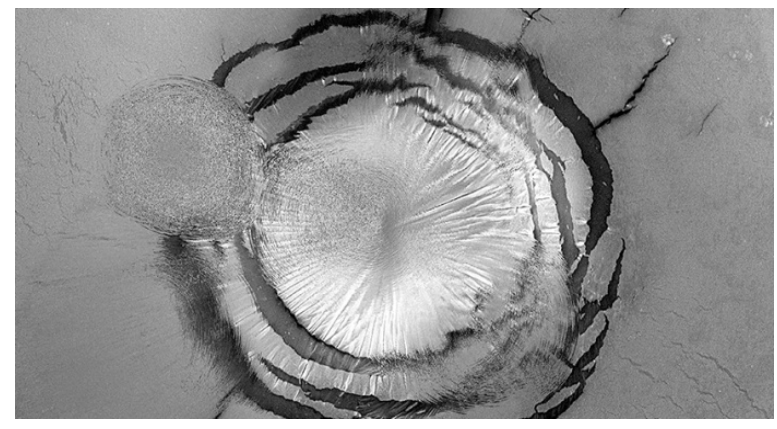

Figure 1: Anastasia Tyurina, Rainwater (detail) 2016, Digital mixed media

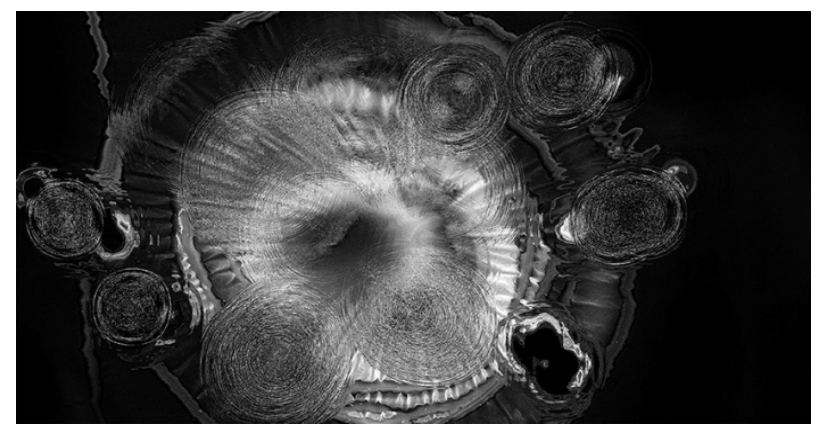

Figure 2: Anastasia Tyurina, Brisbane River (detail) 2016, Digital mixed media

Interacting with the image in this way transforms the work into something that transcends disciplines. It offers a layered meaning, providing audiences with the opportunity of experiencing the fluid and animated qualities of the effects that connects with these qualities in the subject matter: water. The addition of the interactivity and animation introduced by the ripple effect is the expanded mode of 'reading' or appreciation. As well as offering a visual engagement, the work offers an embodied engagement: an important connection to the material significance of water in our lives.
Such digital installations allow the transformative power of water to be explored; they offer new perceptual experiences and, by the artist-codedisplay-audience interaction, can provide a new meaning for scientific images through their everchanging visualisation.

\section{REFERENCES}

Yakhno, T. A., Yakhno, V. G, Sanin, A. G, Sanina, O.A, Pelyushenko, A. S., Egorova, N. A, Terentiev, I.G, Smetanina, S. V., Korochkina, O. V., and Yashukova E. V. (2005) The Informative-Capacity Phenomenon of Drying Drops. IEEE Engineering in Medicine and Biology Magazine, 24(2), pp. 96-102.

Kokornaczyk, M. O, Dinelli, G., Marotti, I., Benedettelli, S., Nani, D., and Betti, L. (2011) SelfOrganized Crystallization Patterns from Evaporating Droplets of Common Wheat Grain Leakages as a Potential Tool for Quality Analysis. The Scientific World Journal, No. 3, 1712-1725.

Burgess, J., Marten, M., Taylor R., McNamee, M., and Stepney, R. (1990) Under the Microscope: A Hidden World Revealed. Cambridge University Press, New York.

Breger, D. (1995) Journey in Microspace: The art of scanning electron microscope. Columbia University Press, New York.

Juliff, T. and Cox, T. (2015) The Post-display Condition of Contemporary Computer Art, emaj, 8, April. 